\section{(6) OPEN ACCESS}

\title{
Cardiac MR and CT imaging in children with suspected or confirmed pulmonary hypertension/ pulmonary hypertensive vascular disease. Expert consensus statement on the diagnosis and treatment of paediatric pulmonary hypertension. The European Paediatric Pulmonary Vascular Disease Network, endorsed by ISHLT and DGPK
}

\author{
Heiner Latus, ${ }^{1}$ Titus Kuehne, ${ }^{2}$ Philipp Beerbaum, ${ }^{3}$ Christian Apitz, ${ }^{4}$ Georg Hansmann, ${ }^{3}$ \\ Vivek Muthurangu, ${ }^{5}$ Shahin Moledina ${ }^{6}$
}

For numbered affiliations see end of article.

\section{Correspondence to} Dr Heiner Latus, Paediatric Heart Center, Justus-LiebigUniversity Giessen, Feulgenstr. 10-12, Giessen 35392 Germany; heiner.latus@ paediat.med.uni-giessen.de

This article is a product of the writing group of the European Paediatric Pulmonary Vascular Disease (PVD) Network (Writing Group Chair: G. Hansmann, Writing Group Co-Chair: C. Apitz). DGPK, German Society of Paediatric Cardiology; ISHLT, International Society of Heart and Lung Transplantation

Received 5 June 2015 Revised 11 October 2015 Accepted 14 October 2015
CrossMark

To cite: Latus $\mathrm{H}$, Kuehne $\mathrm{T}$, Beerbaum $\mathrm{P}$, et al. Heart 2016;102:ii30-ii35.

\section{ABSTRACT}

Childhood pulmonary hypertension (PH) is a heterogenous disease associated with considerable morbidity and mortality. Invasive assessment of haemodynamics is crucial for accurate diagnosis and guidance of medical therapy. However, adequate imaging is increasingly important in children with $\mathrm{PH}$ to evaluate the right heart and the pulmonary vasculature. Cardiac MR (CMR) and computed tomography (CT) represent important non-invasive imaging modalities that may enable comprehensive assessment of right ventricular (RV) function and pulmonary haemodynamics. Here, we present graded consensus recommendations for the evaluation of children with PH by CMR and CT. The article provides a structured approach for the use of CMR and CT imaging, emphasises non-invasive variables of RV function, myocardial tissue and afterload parameters that may be useful for initial diagnosis and monitoring. Furthermore, assessment of pulmonary perfusion and characterisation of the lung parenchyma provides structural information about processes that may cause or be due to $\mathrm{PH}$

\section{INTRODUCTION}

Pulmonary hypertension $(\mathrm{PH})$ as a result of elevated pulmonary vascular resistance (PVR) ultimately leads to right ventricular (RV) failure and premature death when not responsive to therapy. Despite progress in medical treatment, morbidity and mortality is still high, especially in idiopathic pulmonary arterial hypertension (IPAH). RV failure represents the most common cause of death in childhood $\mathrm{PH}$, and therefore, reliable evaluation of $\mathrm{RV}$ function is crucial. ${ }^{1}$

Echocardiography is the most commonly used non-invasive tool for initial assessment, screening and serial follow-up as it allows rapid assessment of RV function and estimation of pulmonary artery pressure. However, this technique can be limited by poor acoustic windows and the complex geometry of the RV. This sometimes makes reliable assessment of RV function using echocardiography difficult. $^{2}$

A more comprehensive assessment of the RV and the pulmonary vasculature is possible by cardiac MR (CMR) and CT. These techniques have become important non-invasive imaging modalities in the management of adult PH. CMR offers the ability to assess ventricular function, blood flow, pulmonary perfusion and myocardial tissue characteristics. The main role of CT is to detect alternative causes of $\mathrm{PH}$ including lung parenchymal disorders, thromboembolic disease and vascular abnormalities such as pulmonary vein stenosis.

In this consensus statement, we review the principles and application of CMR and CT in patients with paediatric $\mathrm{PH}$. The article provides practical recommendations and emphasises non-invasive variables that may be useful for initial diagnosis and monitoring.

\section{METHODS}

The recommendations summarised in table 1 relate to the grading system currently suggested by the European Society of Cardiology and the American Heart Association, and was based on paediatric data only (class, level of evidence). The grading and voting process within the writing group is outlined in the executive summary of this special issue. Computerised searches of the PubMed/MEDLINE bibliographic database were conducted between January 1990 and June 2015. Clinical trials, guidelines and reviews limited to paediatric data were searched using the terms 'pulmonary hypertension', 'children', 'cardiac magnetic resonance' and 'computed tomography'.

\section{CMR protocol}

$\mathrm{CMR}$ in young children is often performed under either sedation or general anaesthesia. However, patients with paediatric $\mathrm{PH}$ are at high risk for cardiac decompensation, and therefore, anaesthesia and sedation come at substantial risk. ${ }^{3}$ If 
Table 1 Recommendations on the use of cardiac magnetic resonance and computed tomography in children with pulmonary hypertension

\begin{tabular}{|c|c|c|}
\hline Recommendations & COR & LOE \\
\hline $\begin{array}{l}\text { CMRI without anaesthesia/sedation is recommended in children with suspected pulmonary hypertension/paediatric pulmonary hypertensive vascular } \\
\text { disease as part of the diagnostic evaluation and during follow-up to assess changes in ventricular function and chamber dimensions }{ }^{6} 7\end{array}$ & I & B \\
\hline $\begin{array}{l}\text { It is recommended that a cMRI study of a child with suspected PH/PPHVD should include the following modules }{ }^{6} \text { : Cine cMRI for the assessment } \\
\text { biventricular volume, function and mass using a stack of axial or short-axis slices covering the entire heart }\end{array}$ & I & B \\
\hline $\begin{array}{l}\text { A cMRI study of a child with suspected PH/PPHVD should include the following modules }{ }^{7} \text { standard 2D flow (PCMRI) measurements at the MPA, RPA, } \\
\text { LPA, AAO }\end{array}$ & I & B \\
\hline A cMRI study of a child with suspected PH/PPHVD may include the following modules: standard 2D flow (PCMRI) measurements at the pulmonary veins & llb & B \\
\hline $\begin{array}{l}\text { A cMRI study of a child with suspected PH/PPHVD may include the following modules: late gadolinium enhancement may be considered for the } \\
\text { assessment of presence and amount of myocardial fibrosis }{ }^{27}\end{array}$ & Illb & C \\
\hline $\begin{array}{l}\text { It is uncertain whether a cMRI study of a child with suspected PH/PPHVD should include simultaneous invasive pressure measurements (cMRI-guided } \\
\text { cardiac catheterisation) to calculate PVR (combined with pulmonary flow measurements) and/or to assess load-independent indices of ventricular } \\
\text { function (combined with ventricular flow measurements) }\end{array}$ & llb & C \\
\hline $\begin{array}{l}\text { A cMRI study of a child with suspected PH/PPHVD may include the following modules: gadolinium contrast-enhanced or non-contrast-enhanced } \\
\text { angiography to assess morphology and size of the pulmonary arteries, the pulmonary arterial tree and to quantify pulmonary perfusion (CE-MRI) }\end{array}$ & Illb & C \\
\hline $\begin{array}{l}\text { It is uncertain whether a cMRI study of a child with suspected PH/PPHVD should include the following modules: assessment of regional RV myocardial } \\
\text { function by cMRI tagging techniques }\end{array}$ & llb & C \\
\hline $\begin{array}{l}\text { It is uncertain whether a CMR study of a child with suspected PH/PPHVD should include the following modules: non-invasive estimation of RV afterload } \\
\text { variables including RVP/PAP/PVR using different proposed cMRI techniques (interventricular septal position, flow measurements, pulmonary distensibility } \\
\text { and elastance, RV-PA coupling) }\end{array}$ & Illb & C \\
\hline High-resolution chest CT with angiography is recommended in the initial assessment of a child with suspected PH/PPHVD & 1 & C \\
\hline In case an obvious cause for PH/PPHVD, such as left-to-right cardiovascular shunt, a chest CT may be omitted. & Illb & C \\
\hline High-resolution chest CT is indicated in every patient being evaluated for lung transplantatiol & 1 & C \\
\hline
\end{tabular}

AAO, ascending aorta; COR, class of recommendation; CMRI, cardiac MRI; LOE, level of evidence; LPA, left pulmonary artery; MPA, main pulmonary artery; PCMR, phase-contrast MR; PH/PPHVD, pulmonary hypertension/paediatric pulmonary hypertensive vascular disease; PVR, pulmonary vascular resistance; PAP, pulmonary artery pressure;

$\mathrm{RV}$, right ventricular; RPA, right pulmonary artery.

anaesthesia or sedation is required, it is important to thoroughly weigh the benefits gained from the information acquired against the risks of anaesthesia in a child with $\mathrm{PH}$. If no sedation is required, e.g in an older child, cardiac CMR is recommended in children with suspected or confirmed $\mathrm{PH} /$ paediatric pulmonary hypertensive vascular disease (PPHVD) as part of the diagnostic evaluation and during follow-up. As with all CMR examinations, it is recommended that protocols are optimised to answer specific questions related to the disease. Below is a list of the main advantages and disadvantages of CMR variables (table 2), a recommended protocol for paediatric $\mathrm{PH}$ (table 3).

Table 2 Advantages and disadvantages of CMR measurements in pulmonary hypertension

\begin{tabular}{|c|c|c|}
\hline Variable & Main advantages & Main disadvantages \\
\hline $\begin{array}{l}\text { RV and LV: EDVI/ESVI/SVI, } \\
\text { myocardial mass }\end{array}$ & $\begin{array}{l}\text { Routinely performed, reliable assessment of cardiac size, RVEDVI/ } \\
\text { LVEDVI/SVI and RV mass index predictors of mortality in adult PH, } \\
\text { initial and follow-up study to study disease progression }\end{array}$ & Observer variance problems depending on standards/training \\
\hline $\mathrm{EF}$ & $\begin{array}{l}\text { Routinely assessed parameter of global ventricular pump function, } \\
\text { RVEF related to outcome in paediatric } \mathrm{PH}\end{array}$ & $\begin{array}{l}\text { Load-dependent parameter of RV function, may miss early systolic } \\
\text { dysfunction }\end{array}$ \\
\hline Blood flow (PCMR) & $\begin{array}{l}\text { Routinely performed, selective blood flow measurements in any } \\
\text { vessel of appropriate size possible, estimation of pulmonary and } \\
\text { systemic blood flow, quantification of shunt flow, low intrastudy and } \\
\text { interstudy reproducibility }\end{array}$ & $\begin{array}{l}\text { Time consuming if several vessels are examined, helical flow } \\
\text { pattern in main PA, no accurate assessment of peak blood flow } \\
\text { velocities (no reliable assessment of pressure gradients), susceptible } \\
\text { to non-flow-related phase errors }\end{array}$ \\
\hline $\begin{array}{l}\text { Late gadolinium enhancement } \\
\text { (LGE) }\end{array}$ & Visualisation of macroscopic myocardial fibrosis & $\begin{array}{l}\text { Contrast agent necessary, longer examination time, conflicting data } \\
\text { regarding prognostic value of LGE in adults, no data in paediatric } \\
\mathrm{PH}\end{array}$ \\
\hline Strain, strain rate & $\begin{array}{l}\text { Additional parameter of myocardial function, assessment of } \\
\text { intraventricular and interventricular dyssynchrony, postprocessing } \\
\text { analysis by tissue tracking software, easy to perform }\end{array}$ & $\begin{array}{l}\text { Not routinely assessed, tagging techniques time consuming, } \\
\text { myocardial feature tracking from cine-SSFP possible but no data } \\
\text { available in paediatric PH for either technique }\end{array}$ \\
\hline Septal curvature & Valid estimation of sPAP and PVR in paediatric PH & Not routinely assessed, postprocessing time \\
\hline T1 mapping & Quantification of diffuse myocardial fibrosis & Only data in experimental model of chronic $\mathrm{PH}$ \\
\hline $\begin{array}{l}\text { Pulmonary artery stiffness: } \\
\text { pulsatility/capacitance/ } \\
\text { distensibility/compliance }\end{array}$ & $\begin{array}{l}\text { Early marker of } \mathrm{PH} \text {; independently associated with the degree of RV } \\
\text { dysfunction, dilation, and hypertrophy in } \mathrm{PH}\end{array}$ & Not routinely assessed, no data in paediatric PH \\
\hline RV-PA coupling & $\begin{array}{l}\text { Easy to calculate, comprehensive analysis of ventricular contractility } \\
\text { and vascular load, correlated with outcome in adult } \mathrm{PH}\end{array}$ & Invasive data necessary, no data in paediatric PH \\
\hline
\end{tabular}


Table 3 Proposed CMR protocol in children and adolescents with suspected or confirmed PH/PPHVD

\begin{tabular}{|c|c|c|}
\hline Assessment & Metrics assessed & Sequence \\
\hline Ventricular volumes & EDVI/ESVI/SVI, EF myocardial mass & $\begin{array}{l}\text { b-SSFP cine imaging. Short axis or transverse slices. Can be acquired in breath-holds, free } \\
\text { breathing or real time }\end{array}$ \\
\hline $\begin{array}{l}\text { Blood flow in RPA, LPA, MPA and } \\
\text { aorta }\end{array}$ & $\begin{array}{l}\text { Calculation of } \mathrm{CO}, \mathrm{Qp}: \mathrm{Qs} \text { and valvar } \\
\text { regurgitation if present }\end{array}$ & $\begin{array}{l}\text { Phase contrast MR. Best acquired using a free-breathing sequence with multiple signal averages } \\
\text { for respiratory compensation }\end{array}$ \\
\hline
\end{tabular}

\section{Ventricular assessment}

Cine CMR is the gold standard for the assessment of biventricular volumes, muscle mass and global pump function. ${ }^{4} 5$ Cine CMR is also highly reproducible, making it ideally suited for serial follow-up examinations to detect changes in RV dimensions and function. ${ }^{6} 7$ Thus, Cine CMR it is the most important component of a paediatric PH CMR. A stack of contiguous short-axis or transverse slices covering both ventricles is used to measure ventricular volumes (figure 1). There are some data to suggest that transverse slices provide more accurate assessment of RV volumes. ${ }^{8} 9$ However, this has not been definitively demonstrated in paediatric $\mathrm{PH}$. It is recommended that a steady-state free precession (SSFP) sequence is used with approximately 20 true phases per cardiac cycle and a slice thickness of between 5 and $8 \mathrm{~mm}$ depending on patient size. This is typically achieved by either short breath-holds or in uncooperative patients free-breathing measurements. Free-breathing cine $\mathrm{CMR}$ can be achieved by using signal averaging or real-time techniques. The clinical importance of cine CMR in the paediatric $\mathrm{PH}$ population has recently been demonstrated in the study by Moledina et al, ${ }^{7}$ which included 100 children and adolescents with $\mathrm{PH}$ of various aetiologies. This study revealed several CMR parameters to correlate with functional class, 6-minute walk distance and invasive haemodynamic measurements such as pulmonary artery pressure. Furthermore, this study revealed the prognostic value of CMR in the children and young adolescents with PH: of all CMR indices, RV ejection fraction and left ventricle (LV) indexed stroke volume were most associated with an increased risk of death or transplantation with a 1 SD decrease in there measures, resulting in a 2.6 -fold and 2.5 -fold increased risk of death, respectively. In another study, Blalock et $a l^{6}$ assessed RV volumes and function by cine CMR in a smaller cohort of 26 patients with $\mathrm{PH}$ aged 2-16 years and found RV parameters abnormal in contrast to healthy individuals. In a follow-up examination in 15 patients, RV volumes, function and LV stroke volume showed no significant change over 1 year, which was probably related to a relatively stable cohort with normal 6-minute walk distances.

\section{Blood flow}

Measurement of blood flow in the ascending aorta, the pulmonary trunk and the right and left pulmonary artery using standard two-dimensional velocity encoded phase contrast MR (PCMR) should always be part of the CMR study (table 4). PCMR allows accurate quantification of cardiac output and shunts, as well as differential lung perfusion and evaluation of valve function. ${ }^{10-12}$ The CMR study may also include the assessment of blood flow in the systemic or pulmonary veins to allow quantification of blood flow through aortopulmonary or venovenous collaterals. Measurement of blood flow by PCMR is performed in a single plane perpendicular to the vessel of interest. PCMR has low interstudy and interobserver/intraobserver variability and is best performed using free-breathing techniques. Breath-hold or realtime PCMR is possible but tends to have lower spatiotemporal resolution. ${ }^{13}$ Quantification of blood flow by MR is affected by complex flow patterns as seen in the dilated pulmonary vasculature (figure 2). This is particularly true in the main pulmonary artery, which is why assessment of flow in the branch pulmonary arteries is recommended. ${ }^{14}$ Assessment of peak velocities is not accurate with PCMR, and reliable quantification of pressure gradients is better with echocardiography.

\section{Anatomical assessment}

Anatomical assessment in children with PH may also be important, particularly if there is a suspicion of congenital heart disease. Contrast-enhanced CMR angiography may be useful in children with $\mathrm{PH}$ for the assessment of vascular abnormalities. Although uncommon in childhood $\mathrm{PH},{ }^{15} \mathrm{MR}$ angiography
Figure 1 Cine images in the four-chamber view (left) of a patient with systemic PA pressures showing right ventricular (RV) dilatation and hypertrophy and an enlarged right atrium. The short-axis view (right) of a patient with severe idiopathic pulmonary hypertension showing a severely dilated and hypertrophied RV with end-systolic septal bowing to the left. The green and red lines represent the curvature of the interventricular septum and the left ventricle free wall.

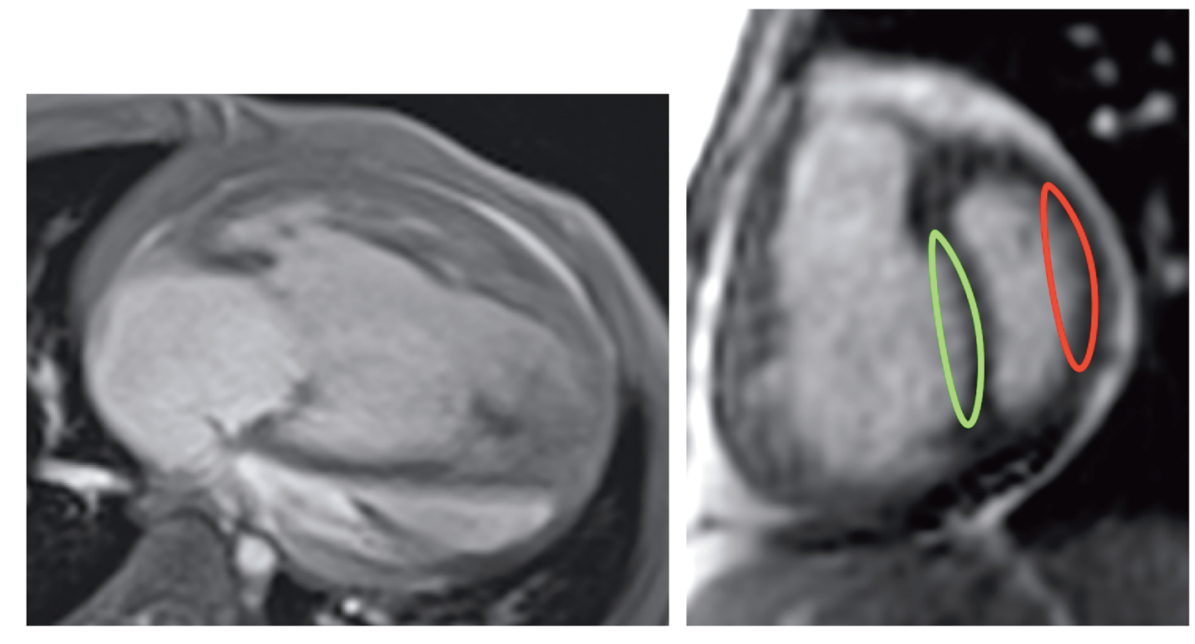

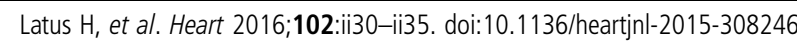


Table 4 Summary of CMR and CT studies in children and adolescents with pulmonary hypertension and studies providing CMR reference values in a healthy population

\begin{tabular}{|c|c|c|c|c|c|}
\hline Reference & No. & Patients & Age (years) & Parameters & Outcome \\
\hline \multicolumn{6}{|l|}{ CMR } \\
\hline Blalock et $a l^{6}$ & 26 & IPAH & $2-16$ & RVEDV, RVEF, LVEDV, LVSV & Abnormal compared with controls, stable over 1 year \\
\hline Moledina et $\mathrm{al}^{7}$ & 100 & $\begin{array}{l}\text { IPAH, CHD, } \\
\text { miscellaneous }\end{array}$ & $0.5-17.6$ & RV and LV: EDV, ESV, SV, EF, MM & $\begin{array}{l}\text { CMR measures correlate with clinical status and prognosis } \\
\text { (RVEF and LVSV) }\end{array}$ \\
\hline Pandya et $a l^{36}$ & 50 & IPAH, CHD, LD & $0.45-16.5$ & $\begin{array}{l}\text { CMR-augmented cardiac catheterisation, } \\
\text { real-time CMR sequence, septal curvature } \\
\text { metrics }\end{array}$ & $\begin{array}{l}\text { Septal curvature metrics are able to estimate RV afterload } \\
\text { and track acute changes in pulmonary haemodynamics } \\
\text { during vasodilator testing }\end{array}$ \\
\hline \multicolumn{6}{|l|}{$\mathrm{CT}$} \\
\hline Moledina et $a l^{7}$ & 31 & CHD, IPAH, other & $0.7-19.1$ & $\begin{array}{l}\text { Fractal dimension of CT pulmonary } \\
\text { angiograms }\end{array}$ & $\begin{array}{l}\text { Fractal dimension correlates with clinical status, } \\
\text { haemodynamics and survival }\end{array}$ \\
\hline \multicolumn{6}{|l|}{ Normal values CMR } \\
\hline Robbers-Visser et $a l^{41}$ & 60 & $\begin{array}{l}\text { Healthy children and } \\
\text { adolescents }\end{array}$ & $8-17$ & RV and LV: EDV, ESV, MM & $\begin{array}{l}\text { Gender-specific normative data for biventricular function, } \\
\text { volume and mass }\end{array}$ \\
\hline Sarikouch et $a l^{42}$ & 99 & $\begin{array}{l}\text { Healthy children and } \\
\text { adolescents }\end{array}$ & $8-20$ & RV and LV: EDV, ESV, MM & $\begin{array}{l}\text { Percentiles for ventricular mass and volume in children } \\
\text { aged } 8-20 \text { years }\end{array}$ \\
\hline
\end{tabular}

may also detect vascular obstruction caused by pulmonary thromboembolism (figure 3) or peripheral pulmonary artery stenoses. $^{16-18}$ Conventional contrast-enhanced MR angiography is acquired in a breath-hold. Unfortunately, due to the high prevalence of dyspnoea in these patients, the long breath-holds required may be difficult to perform. New techniques such as time-resolved MR angiography may solve problems associated with breath-holding as well as provide quantitative information about perfusion heterogeneity. ${ }^{19}$ Due to current limitations, MR angiography is not recommended as a sole screening test for chronic thromboembolic $\mathrm{PH}$ and most international guideline groups continue to recommend ventilation perfusion scintigraphy followed by pulmonary angiography or CT pulmonary angiography instead. MR angiography is also useful in detection of congenital vascular causes of $\mathrm{PH}$, such as patent ductus arteriosus. However, for assessment of intracardiac causes of $\mathrm{PH}$, such as a ventricular septal defect (VSD), when unable to characterise by echocardiography, three-dimensional SSFP whole heart imaging is recommended. ${ }^{20}$ Since it is respiratory navigated and ECG triggered, there is no necessity for breathholding and it is well suited to this patient population.

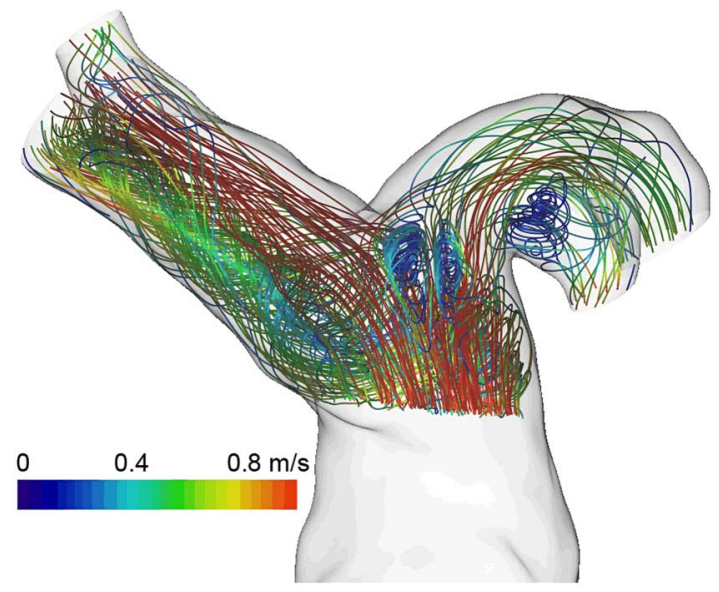

Figure 2 MR image of the pulmonary artery in a patient with pulmonary hypertension. Note abnormal recirculating blood flow patterns at the level of the dilated left and right pulmonary artery.

\section{Myocardial tissue characterisation}

Increased RV afterload is associated with myocyte apoptosis, inflammation and fibrosis. ${ }^{21}$ Thus, quantification of myocardial fibrosis may be a useful indicator of disease severity. Late gadolinium enhancement (LGE) is typically seen at the RV insertion points (figure 4) and has been found to be related to abnormal pulmonary haemodynamics and RV systolic dysfunction. ${ }^{22-28}$ Data about the presence of LGE and quantitative data on diffuse RV myocardial fibrosis by mapping techniques and/or extracellular volume quantification are lacking in childhood $\mathrm{PH}$. The prevalence, haemodynamic consequences and prognostic value of delayed enhancement in childhood $\mathrm{PH}$ need to be defined in the future.

\section{Areas of further development}

Combined measurement of invasive pressure and MR-based volume and flow data by CMR augmented cardiac catheterisation has been described by several groups. ${ }^{29-32}$ So far, it is uncertain whether simultaneous pressure measurements should be included in a CMR study of a child with suspected $\mathrm{PH} /$ PPHVD as experience is currently limited to a small number of specialised centres. CMR-augmented catheterisation may offer

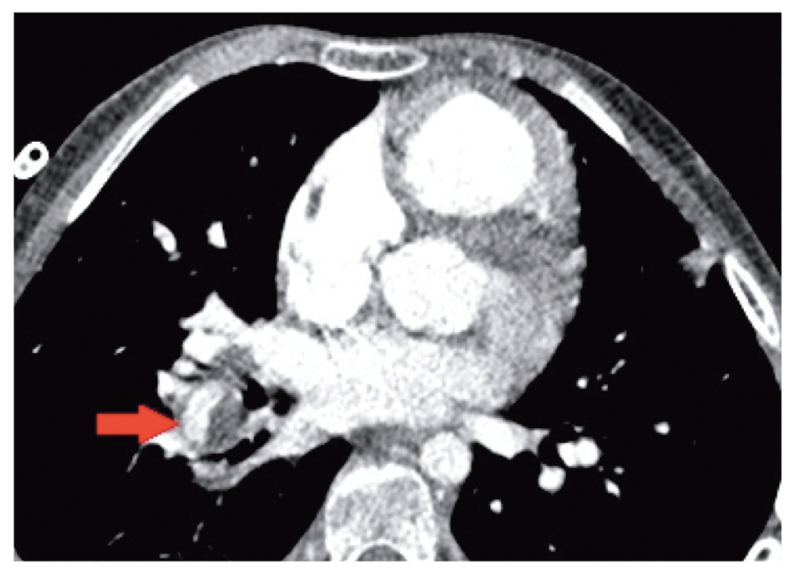

Figure $3 \mathrm{CT}$ image for a patient with chronic thromboembolic pulmonary hypertension. The arrow points to the right lower lobe pulmonary artery, which is partially occluded by thrombus. 


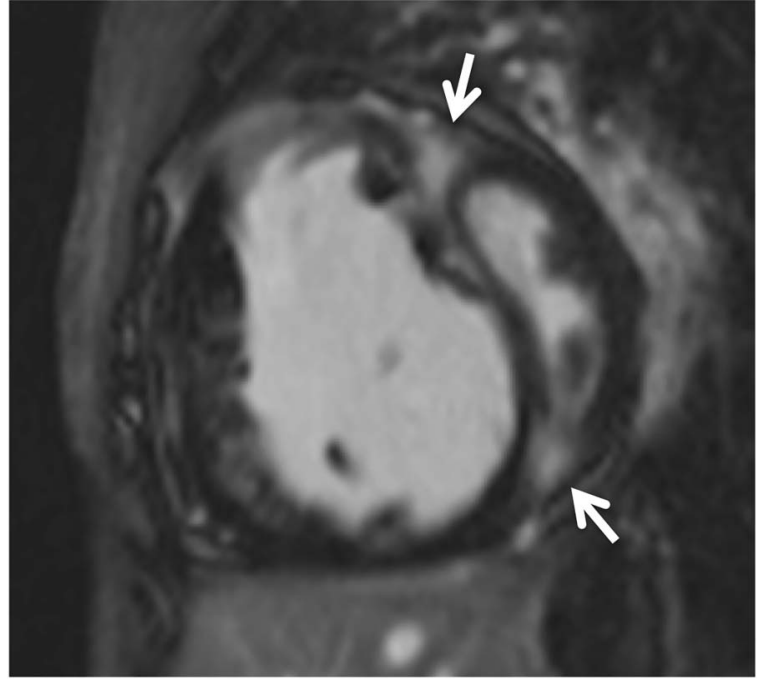

Figure 4 Late gadolinium enhancement image in the short-axis view in a 7-year-old patient with suprasystemic idiopathic pulmonary arterial hypertension. Note the areas of regional fibrosis typically found at the right ventricular insertion points (arrows).

some advantages including a precise calculation of PVR due to a more reliable quantification of pulmonary flow volume compared with thermodilution technique or oximetry. ${ }^{31} 32$

Uncertainty exists regarding non-invasive estimation of RV afterload parameters such as RV pressure, PAP and PVR by $\mathrm{CMR}$ imaging in children with $\mathrm{PH}$ as these techniques are primarily validated in adults. ${ }^{33}{ }^{34}$ Analysis of interventricular septal curvature by CMR (figure 1) has been found to correlate with mean PAP and indexed pulmonary vascular resistance (PVRi) in adults and in children. ${ }^{35}{ }^{36}$ Septal curvature metrics also reliably tracked changes in haemodynamics during acute vasodilator testing, making it potentially useful for afterload assessment during follow-up. ${ }^{36}$ Cine CMR assessment of pulmonary distensibility may be used to detect $\mathrm{PH}$ and has been shown to correlate with outcome in small studies.

\section{CT in paediatric $\mathrm{PH}$}

The principal role of CT in assessment of $\mathrm{PH}$ is to demonstrate features of secondary forms of $\mathrm{PH}$. More specifically, this modality is suited to assessing for parenchymal lung disease, vascular abnormalities and thromboembolic disease. It may also provide information on cardiac, mediastinal abnormalities and may suggest a diagnosis of $\mathrm{PH}$. As such, it features as an early investigation for patients suspected of $\mathrm{PH}$ in various guidelines. ${ }^{37}$ Multislice CT has made it possible to image the thorax at high resolution in under $5 \mathrm{~s}$ producing isotropic data at submillimetre resolution.

Computed tomography pulmonary angiography (CTPA) protocols vary depending upon the type of scanner, the availability of ECG-gating among other factors. Nevertheless, the aim of any CTPA study is to optimally opacify the right heart chambers and pulmonary arterial tree and limit cardiac and diaphragmatic motion artefact.

CT, when performed for the investigation of other conditions, may raise the suspicion of $\mathrm{PH}$. A recent systematic review and meta-analysis in adult CT suggests the pulmonary artery dilatation and pulmonary artery to ascending aorta diameter ratio to have high specificity for PH. Similar data are not yet available in children. $^{38}$
CT is the modality of choice for the detection of parenchymal lung disease such as chronic lung disease and developmental abnormalities. Identification and quantification of lung disease may be particularly helpful in paediatric $\mathrm{PH}$, where history of dyspnoea may be non-specific and when younger children may not reliably perform pulmonary function testing. In addition, prevalence of congenital lung abnormalities is likely to be higher in children than in adults. In addition, CT is highly sensitive for the identification of pulmonary veno-occlusive disease (PVOD) due to its characteristic features: thickened interlobular septa, poorly defined nodular opacities and lymphadenopathy. ${ }^{39}$ POVD is an important differential diagnosis because of its impact it has on management strategy.

Chronic thromboembolic disease (CTED) is an important diagnosis to exclude in patients with $\mathrm{PH}$. Even though the incidence is likely to be low in children with $\mathrm{PH}$, the possibility to surgically cure this condition warrants assessment. Due to its rarity, paediatric-specific data from on are lacking; however, by extrapolation from extensive research in adult CTED, CT pulmonary angiography is the first-line cross-sectional imaging modality for the evaluation of chronic thromboembolic $\mathrm{PH}$ in patients with suggestive ventilation-perfusion scan. ${ }^{40}$ Recent data suggest that modern CT technology in experienced hands may have nearly equal sensitivity and specificity to V/Q scanning. Importantly, CT angiography can distinguish between surgically amenable disease from distal disease. ${ }^{37}$

CT pulmonary angiography is well suited to assessment of great vessel anatomy and to the detection of extracardiac shunt lesions, for example, persistent arterial duct, aortopulmonary collaterals; however, operators should be aware of the possibility of false negative results. While echocardiography remains the firstline imaging modality for assessing congenital cardiac and vascular abnormalities, CTPA remains an extremely useful adjunct.

Protocols should be developed to minimise exposure to ionising radiation and follow-up CTs should be kept to a minimum. Where possible it is recommended that children undergo low-dose prospectively ECG-gated CT as it provides better image quality.

\section{Author affiliations}

${ }^{1}$ Pediatric Heart Centre, Justus-Liebig-University, Giessen, Germany

${ }^{2}$ Unit of Cardiovascular Imaging, Department of Congenital Heart Disease and Pediatric Cardiology, German Heart Institute Berlin, Berlin, Germany

${ }^{3}$ Department of Pediatric Cardiology and Critical Care, Hannover Medical School, Hannover, Germany

${ }^{4}$ Department of Pediatric Cardiology, University Childrens Hospital UIm, Ulm, Germany

${ }^{5}$ Cardiovascular MRI Department, Great Ormond Street Hospital for Children, London, UK

${ }^{6}$ National Paediatric Pulmonary Hypertension Service UK, Great Ormond Street Hospital for Children, London, UK

Funding $\mathrm{HL}$ currently receives grant funding from the Pitzer Stiftung (Bad Nauheim, 12-147), the German Society of Paediatric Cardiology (DGPK) and the Fördergemeinschaft Deutsche Kinderherzzentren (W-GI-017/2013). TK currently receives grants from the German Federal Ministry for Education and Science (BMBF SysMed2-012/Az 0101-31P8971), from the European Commission (EUFP7 and EU FP7) and the German Research Foundation (DFG KU1329/10). PB receives grant funding from the Medical Research Council (UK) (MRSBACR), the

Fördergemeinschaft Deutsche Kinderherzzentren (W-H-003/2014) and the Kompetenznetz angeborene Herzfehler (FKZ 01GI0210). CA currently receives grant funding from Stiftung Kinderherz (2511-10-13-001) and Behring-Röntgen-Stiftung (59-0018). GH currently receives grant support from the German Research Foundation (DFG; HA 4348/2-1), Fördergemeinschaft deutsche Kinderherzzentren (W-H-001-2014), Stiftung Kinderherz (2511-6-13-011). VM receives grant support from the British Heart Foundation and Great Ormond Street Hospital Charity.

This Heart supplement was produced with support from an unrestricted educational grant from Actelion Pharmaceuticals Germany GmbH, Bayer Pharma AG, and Pfizer Inc. None of these organisations had any influence on the composition of 
the writing group or the content of the articles published in this supplement. Open Access publication of this article was sponsored by Actelion Pharmaceuticals Germany GmbH.

Competing interests SM has acted as a consultant for Bayer pharmaceuticals.

Provenance and peer review Commissioned; externally peer reviewed.

Open Access This is an Open Access article distributed in accordance with the Creative Commons Attribution Non Commercial (CC BY-NC 4.0) license, which permits others to distribute, remix, adapt, build upon this work non-commercially, and license their derivative works on different terms, provided the original work is properly cited and the use is non-commercial. See: http://creativecommons.org/ licenses/by-nc/4.0/

\section{REFERENCES}

1 Tonelli AR, Arelli V, Minai OA, et al. Causes and circumstances of death in pulmonary arterial hypertension. Am J Respir Crit Care Med 2013;188:365-9.

2 Vonk Noordegraaf A, Haddad F, Bogaard HJ, et al. Noninvasive imaging in the assessment of the cardiopulmonary vascular unit. Circulation 2015;131: 899-913.

3 Taylor CJ, Derrick G, McEwan A, et al. Risk of cardiac catheterization under anaesthesia in children with pulmonary hypertension. $\mathrm{Br} J$ Anaesth 2007;98:657-61.

4 Grothues F, Moon JC, Bellenger NG, et al. Interstudy reproducibility of right ventricular volumes, function, and mass with cardiovascular magnetic resonance. Am Heart J 2004;147:218-23.

5 Katz J, Whang J, Boxt LM, et al. Estimation of right ventricular mass in normal subjects and in patients with primary pulmonary hypertension by nuclear magnetic resonance imaging. J Am Coll Cardiol 1993;21:1475-81.

6 Blalock S, Chan F, Rosenthal $D$, et al. Magnetic resonance imaging of the right ventricle in pediatric pulmonary arterial hypertension. Pulm Circ 2013;3:350-5.

7 Moledina S, Pandya B, Bartsota M, et al. Prognostic significance of cardiac magnetic resonance imaging in children with pulmonary hypertension. Circ Cardiovasc Imaging 2013;6:407-14.

8 Fratz S, Schuhbaeck A, Buchner C, et al. Comparison of accuracy of axial slices versus short-axis slices for measuring ventricular volumes by cardiac magnetic resonance in patients with corrected tetralogy of fallot. Am J Cardiol 2009;103:1764-9.

9 Alfakih K, Plein S, Bloomer T, et al. Comparison of right ventricular volume measurements between axial and short axis orientation using steady-state free precession magnetic resonance imaging. J Magn Reson Imaging 2003;18: 25-32.

10 Bell A, Beerbaum P, Greil G, et al. Noninvasive assessment of pulmonary artery flow and resistance by cardiac magnetic resonance in congenital heart diseases with unrestricted left-to-right shunt. JACC Cardiovasc Imaging 2009;2:1285-91.

11 Beerbaum $\mathrm{P}$, Korperich $\mathrm{H}$, Barth $\mathrm{P}$, et al. Noninvasive quantification of left-to-right shunt in pediatric patients: phase-contrast cine magnetic resonance imaging compared with invasive oximetry. Circulation 2001;103:2476-82.

12 Robertson MB, Kohler U, Hoskins PR, et al. Quantitative analysis of PC MRI velocity maps: pulsatile flow in cylindrical vessels. Magn Reson Imaging 2001;19: 685-95.

13 Körperich $\mathrm{H}$, Gieseke J, Barth P, et al. Flow volume and shunt quantification in pediatric congenital heart disease by real-time magnetic resonance velocity mapping: a validation study. Circulation 2004;109:1987-93.

14 Mauritz GJ, Marcus JT, Boonstra A, et al. Non-invasive stroke volume assessment in patients with pulmonary arterial hypertension: left-sided data mandatory. J Cardiovasc Magn Reson 2008;10:51.

15 Stein PD, Kayali F, Olson RE. Incidence of venous thromboembolism in infants and children: data from the National Hospital Discharge Survey. J Pediatr 2004; 145:563-5.

16 Rajaram S, Swift AJ, Telfer A, et al. 3D contrast-enhanced lung perfusion MRI is an effective screening tool for chronic thromboembolic pulmonary hypertension: results from the ASPIRE Registry. Thorax 2013;68:677-8.

17 Rajaram S, Swift AJ, Capener D, et al. Diagnostic accuracy of contrast-enhanced MR angiography and unenhanced proton MR imaging compared with CT pulmonary angiography in chronic thromboembolic pulmonary hypertension. Eur Radiol 2012;22:310-17.

18 Ohno Y, Koyama H, Yoshikawa T, et al. Contrast-enhanced multidetector-row computed tomography vs. Time-resolved magnetic resonance angiography vs. contrast-enhanced perfusion MRI: assessment of treatment response by patients with inoperable chronic thromboembolic pulmonary hypertension. J Magn Reson Imaging 2012;36:612-23.

19 Scott JA. Pulmonary perfusion patterns and pulmonary arterial pressure. Radiology 2002;224:513-18.
20 Monney P, Piccini D, Rutz T, et al. Single centre experience of the application of self navigated 3D whole heart cardiovascular magnetic resonance for the assessment of cardiac anatomy in congenital heart disease. I Cardiovasc Magn Reson 2015;17:55.

21 Bogaard HJ, Abe K, Vonk Noordegraaf A, et al. The right ventricle under pressure: cellular and molecular mechanisms of right-heart failure in pulmonary hypertension. Chest 2009;135:794-804.

22 Sanz J, Dellegrottaglie S, Kariisa M, et al. Prevalence and correlates of septal delayed contrast enhancement in patients with pulmonary hypertension. Am J Cardiol 2007;100:731-5.

23 McCann GP, Beek AM, Vonk-Noordegraaf A, et al. Delayed contrast-enhanced magnetic resonance imaging in pulmonary arterial hypertension. Circulation 2005;112:e268

24 McCann GP, Gan CT, Beek AM, et al. Extent of MRI delayed enhancement of myocardial mass is related to right ventricular dysfunction in pulmonary artery hypertension. AJR Am J Roentgenol 2007;188:349-55.

25 Blyth KG, Groenning BA, Martin TN, et al. Contrast enhanced-cardiovascular magnetic resonance imaging in patients with pulmonary hypertension. Eur Heart J 2005;26:1993-9.

26 Shehata ML, Lossnitzer D, Skrok J, et al. Myocardial delayed enhancement in pulmonary hypertension: pulmonary hemodynamics, right ventricular function, and remodeling. AJR Am J Roentgenol 2011;196:87-94.

27 Freed BH, Gomberg-Maitland M, Chandra S, et al. Late gadolinium enhancement cardiovascular magnetic resonance predicts clinical worsening in patients with pulmonary hypertension. J Cardiovasc Magn Reson 2012;14:11.

28 Swift AJ, Rajaram S, Capener D, et al. LGE Patterns in Pulmonary Hypertension Do Not Impact Overall Mortality. JACC Cardiovasc Imaging 2014;7:1209-17.

29 Kuehne T, Yilmaz S, Steendijk P, et al. Magnetic resonance imaging analysis of right ventricular pressure-volume loops: in vivo validation and clinical application in patients with pulmonary hypertension. Circulation 2004;110:2010-16.

30 Kuehne T, Yilmaz S, Schulze-Neick I, et al. Magnetic resonance imaging guided catheterisation for assessment of pulmonary vascular resistance: in vivo validation and clinical application in patients with pulmonary hypertension. Heart 2005;91: 1064-9.

31 Muthurangu $\mathrm{V}$, Atkinson $\mathrm{D}$, Sermesant $\mathrm{M}$, et al. Measurement of total pulmonary arterial compliance using invasive pressure monitoring and MR flow quantification during MR-guided cardiac catheterization. Am I Physiol Heart Circ Physiol 2005;289:H1301-6.

32 Muthurangu V, Taylor A, Andriantsimiavona R, et al. Novel method of quantifying pulmonary vascular resistance by use of simultaneous invasive pressure monitoring and phase-contrast magnetic resonance flow. Circulation 2004;110:826-34.

33 García-Alvarez A, Fernández-Friera L, Mirelis JG, et al. Non-invasive estimation of pulmonary vascular resistance with cardiac magnetic resonance. Eur Heart J 2011;32:2438-45.

34 Swift AJ, Rajaram S, Campbell MJ, et al. Prognostic value of cardiovascular magnetic resonance imaging measurements corrected for age and sex in idiopathic pulmonary arterial hypertension. Circ Cardiovasc Imaging 2014;7:100-6.

35 Dellegrottaglie S, Sanz J, Poon M, et al. Pulmonary hypertension: accuracy of detection with left ventricular septal-to-free wall curvature ratio measured at cardiac MR. Radiology 2007;243:63-9.

36 Pandya B, Quail MA, Steeden JA, et al. Real-time magnetic resonance assessment of septal curvature accurately tracks acute hemodynamic changes in pediatric pulmonary hypertension. Circ Cardiovasc Imaging 2014;7:706-13.

37 Galie N, Humbert M, Vachiery JL, et al. 2015 ESC/ERS Guidelines for the diagnosis and treatment of pulmonary hypertension: The Joint Task Force for the Diagnosis and Treatment of Pulmonary Hypertension of the European Society of Cardiology (ESC) and the European Respiratory Society (ERS) Endorsed by: Association for European Paediatric and Congenital Cardiology (AEPC), International Society for Heart and Lung Transplantation (ISHLT). Eur Heart J 2016;37:67-119.

38 Shen $\mathrm{Y}$, Wan C, Tian P, et al. CT-base pulmonary artery measurement in the detection of pulmonary hypertension: a meta-analysis and systematic review. Medicine (Baltimore) 2014;93:e256.

39 Woerner C, Cutz E, Yoo SJ, et al. Pulmonary venoocclusive disease in childhood. Chest 2014;146:167-74.

40 Soler X, Kerr KM, Marsh JJ, et al. Pilot study comparing SPECT perfusion scintigraphy with CT pulmonary angiography in chronic thromboembolic pulmonary hypertension. Respirology 2012;17:180-4.

41 Robbers-Visser D, Boersma E, Helbing WA. Normal biventricular function, volumes, and mass in children aged 8 to 17 years. Journal of magnetic resonance imaging: JMRI 2009;29:552-9.

42 Sarikouch S, Peters B, Gutberlet M, et al. Sex-specific pediatric percentiles for ventricular size and mass as reference values for cardiac MRI: assessment by steadystate free-precession and phase-contrast MRI flow. Circulation Cardiovascular imaging 2010;3:65-76. 